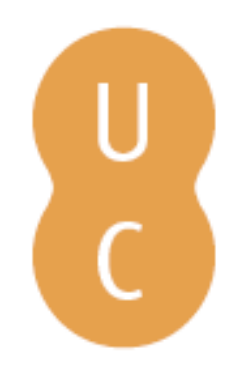

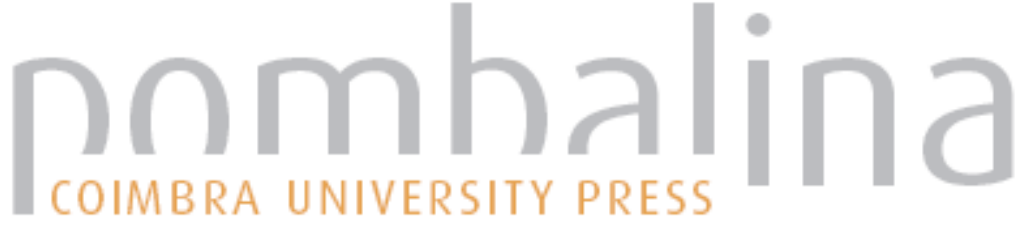

\section{Nabónido e o final do Império Neobabilónico}

Autor(es): $\quad$ Santos, António Ramos dos

Publicado por: Imprensa da Universidade de Coimbra

URL

persistente: URI:http://hdl.handle.net/10316.2/45219

DOI: $\quad$ DOI:https://doi.org/10.14195/978-989-26-1626-1_10

Accessed : $\quad$ 26-Apr-2023 06:33:32

A navegação consulta e descarregamento dos títulos inseridos nas Bibliotecas Digitais UC Digitalis, UC Pombalina e UC Impactum, pressupõem a aceitação plena e sem reservas dos Termos e Condições de Uso destas Bibliotecas Digitais, disponíveis em https://digitalis.uc.pt/pt-pt/termos.

Conforme exposto nos referidos Termos e Condições de Uso, o descarregamento de títulos de acesso restrito requer uma licença válida de autorização devendo o utilizador aceder ao(s) documento(s) a partir de um endereço de IP da instituição detentora da supramencionada licença.

Ao utilizador é apenas permitido o descarregamento para uso pessoal, pelo que o emprego do(s) título(s) descarregado(s) para outro fim, designadamente comercial, carece de autorização do respetivo autor ou editor da obra.

Na medida em que todas as obras da UC Digitalis se encontram protegidas pelo Código do Direito de Autor e Direitos Conexos e demais legislação aplicável, toda a cópia, parcial ou total, deste documento, nos casos em que é legalmente admitida, deverá conter ou fazer-se acompanhar por este aviso.

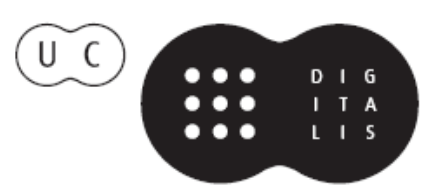




\section{Arqueologias de Império}

\section{Delfim Leão, José Augusto Ramos, Nuno Simões Rodrigues (coords.)}

IMPRENSA DA UNIVERSIDADE DE COIMBRA 


\title{
NABÓNIDO E O FINAL Do IMPÉRIO NEOBABILÓNICO ${ }^{1}$ (Nabonidus and the end of the Neobabilonian Empire)
}

\author{
António Ramos dos Santos \\ (ajr-santos@sapo.pt; ORCID: 0000-0002-6610-9733) \\ Universidade de Lisboa, Faculdade de Letras, Centro de História
}

\begin{abstract}
Resumo - Este estudo trata a figura de Nabónido, o último rei do império neobabilónico. Pretende-se apresentar uma breve biografia, expondo eventos decorridos ao longo do século VI a. C., bem como analisar a questão do poder real e respetiva subdivisão, relacionando-o com eventos de instabilidade política, em particular a sua deslocação à Arábia em 553 a.C.
\end{abstract}

Palavras-Chave: Nabónido; Babilónia; Imperialismo; Arábia; Teima.

Aвstract - This study regards the figure of Nabonidus, the last king of the Neobabilonian empire. It is intended to present a brief biography, exposing events which occurred throughout the $6^{\text {th }}$ century BCE, and to analyse the matter of royal power and its subdivision, relating it to events of political instability, particularly relating to the Arabian expedition of 553BCE.

Keywords: Nabonidus; Babilonia; Imperialism; Arabia; Tayma.

Não se sabe praticamente nada acerca das atividades do último rei de Babilónia antes da sua subida ao trono. Pensou-se que desempenhara o cargo de prefeito durante o reinado de Nabucodonosor, porque aparece um personagem chamado Nabónido que tinha esse título, citado em 597, num documento. Mas tal implicava que tivesse uma vintena de anos e, consequentemente, assumido o poder com a idade de 70 anos. O que parece pouco provável, devendo-se distinguir os personagens. Por outro lado, a estela de Pognon ${ }^{2}$ parece indicar um nascimento tardio, tendo a sua mãe dado à luz em 610-600, mas não mais tarde. Segundo elementos informativos procedentes da estela de Adad-guppi ${ }^{3}$,

\footnotetext{
${ }^{1}$ Este trabalho foi apoiado por Fundos Nacionais através da FCT - Fundação para a Ciência e a Tecnologia no âmbito do projeto UID/HIS/04311/2013.

${ }^{2}$ Veja-se Beaulieu 1989, 70.

${ }^{3}$ Ver ADAD-GUPPI - IM-gu-up-pi-I (649-547a.C.) - Mãe do rei Nabónido da X dinastia de Babilónia (dinastia caldaica) e mulher conhecida sobretudo pelas suas estelas - uma com uma autobiografia - de Kharran, cidade nativa e onde foi devota (palikhtu), como sacerdotisa, do templo Ekhulkhul, dedicado ao deus Sîn (deus lua). Soube demonstrar a sua piedade, também demonstrada às divindades Ningal, Nusku e Sadarnunna, no seu filho, fazendo por ele tudo quanto foi necessário para introduzi-lo na corte de Nabucodonosor II e de Neriglissar. Alcançado esse objectivo, Nabónido, aproveitando um golpe militar produzido contra Labashi-Marduk, com um reinado efémero, ficou com o controlo de Babilónia. Segundo a documentação existente, Adad-guppi, morreu centenária (102 anos)
} 
esta terá introduzido Nabónido na corte de Nabucodonosor e de Neriglissar tendo recebido uma educação de príncipe na sequência. Ignoram-se os motivos do movimento sedicioso que o levou ao trono, assim como a data da reconstrução do templo de Harran. Nabónido terá empreendido os trabalhos após a sua estada em Harran. Este facto é contraditório com uma inscrição de Harran segundo a qual o rei empreendeu os trabalhos depois da sua permanência em Teima. Este testemunho contradiz uma outra inscrição real neobabilónica segundo a qual o Ehulhul ${ }^{4}$ foi terminado depois de 553.

Mas o enigma principal deste reinado reside no motivo da sua grande permanência na Arábia. Nenhum dos argumentos invocados, desde o querer vigiar o Egito enquanto enfrentava os saqueadores árabes, tinha pedido instalar-se na Palestina e enviar um chefe militar a Teima. Nada prova que o comércio do golfo Pérsico fora então desviado até à península arábica e que fora suficientemente importante para justificar a presença do soberano num oásis perdido. Apenas resta o motivo religioso, isto é, a atração de um grande centro lunar.

Nabónido controlou o país durante 17 anos, através da mediação do filho, de quem não parece ter havido oposição. $\mathrm{O}$ último rei do Império babilónico foi uma figura estranha cujas intenções políticas escapam quase por completo. Filho de um governador, provavelmente de origem aramaica, apesar do seu nome babilónico, Nabu-balatsu-iqbi, e de uma sacerdotisa do deus Sîn de Harran, Adad-guppi, Nabónido não era de ascendência real, como reconhecido nas estelas de Hilleh e de Harran. Entronizado por uma conspiração, pretendia ser o continuador de Neriglissar e de Nabucodonosor e mesmo dos grandes soberanos da Assíria.

As suas inscrições e a autobiografia da sua mãe, redigida sob a sua supervisão, refletem uma vontade de continuidade imperial. Não pode negar-se a influência desta mulher na devoção de seu filho por Sîn e que parece ter ditado as suas decisões políticas mais importantes.

Ao ter lugar a sua subida ao trono, em 556, Nabónido teve uma visão na

em Dur-Karashu, na região de Sippar. O seu filho Nabónido, retirado no oásis árabe de Teima, não compareceu ao seu funeral. Na época de Assurbanípal, residiu em Harrân em 649 a. C. e cuja história é conhecida através de uma pseudo-autobiografia, gravada numa estela que integrada seguidamente na estrutura da mesquita da atual povoação de Eski Harrân. Antes de morrer em 547, ela pode ver o seu filho Nabónido, o último dos reis neobabilónicos, empreender a restauração do culto no Ehulhul, saqueado pelos Medos. A sua autobiografia foi redigida de acordo com as instruções de Nabónido, e guardada no templo do deus Sîn em Hârran. Adad-guppi estava muito ligada a este centro religioso, do qual ela era provavelmente originária, e manifestava uma devoção particular ao deus Sîn, deus da Lua, sem ter nunca exercido uma função religiosa a ele ligada; é sem dano que ela é apresentada frequentemente como uma sacerdotisa de Sîn de Hârran; a qualificação de «devota» do deus seria mais apropriada. Na sua pseudo-autobiografia apraza o reinado de 42 anos a Assurbanípal, isto é, até 627 a.C.

${ }^{4}$ O templo de Sîn em Harran. Cf. Beaulieu 1989, 73. 
qual Marduk lhe ordenava a reconstrução do Ehulhul, o templo de Sîn em Harran, que permanecera em ruínas desde a expedição de 610. O rei não via possibilidade em cumprir a missão, visto que por essa época os Medos ocupavam o país ${ }^{5}$. O deus acalmou os temores do rei anunciando o desaparecimento dos Medos. Em 555, Nabónido mudou-se para Larsa para resolver vários problemas administrativos. Durante três anos, reavivou uma série de expedições sírias, que o levariam até aos confins de Edom.

No ano 3, isto é, em 553, a profecia divina cumpriu-se. Ciro, rei de Anzan há seis anos, sublevou-se contra Astíages e as tropas medas abandonaram a região de Harran. Nabónido apressou-se a reconstruir o Ehulhul, com grande indignação por parte do clero de Marduk. Para além disso, a situação económica devia ser pouco favorável e uma série de distúrbios tiveram lugar em Babilónia, Borsippa, Nippur, Ur, Uruk e Larsa. Contudo, o rei não abandonou o seu propósito e tomou a decisão de partir para a Arábia após ter confiado o governo de Babilónia ao seu filho Bel-sharra-usur ${ }^{6}$. Nabónido dirigiu-se ao oásis de Teima que foi possivelmente tomado em 552, assim como as cidades de Dadanu, Padakku, Hibra, Iadihu e Iatribu. Permaneceu dez anos na Arábia, impedindo assim a celebração das festas do Ano Novo em Babilónia. Durante este tempo, a situação internacional evoluiu rapidamente com a ascensão de Ciro e dos Persas.

A permanência do rei de Babilónia em Teima é um enigma. O único motivo aparente é de tipo religioso: Teima era um grande centro lunar. Naturalmente existem dúvidas em invocar este factor. No entanto terá sido importante. A devoção de Nabónido a Sîn era grande e este intentou impor o culto deste deus à própria Babilónia, levando à revolta dos sacerdotes, já exasperados pelo incremento do controlo real sob a administração dos templos.

O controlo das rotas comerciais, a recolha de tributo, ou qualquer outra operação militar ou comercial poderia ser assegurada por um governador em Teima e pelo estacionamento permanente de tropas. A presença do rei não era necessária e pode ser explicada como o resultado de uma crise política em Babilónia. De acordo com o próprio Nabónido, a partida para a Arábia foi provocada pela falta de piedade dos Babilónios que negligenciaram a liderança de Sîn e cometeram faltas contra ele. Todavia, não existe prova de uma rebelião, em Babilónia, no $1^{\circ}$ ano do seu reinado, embora devesse ter havido alguma oposição às suas crenças religiosas e a ortodoxia tenha sido restabelecida por

${ }^{5} \mathrm{O}$ tema da presença dos Medos em Harran continua em discussão. Alguns autores afirmam que Harran foi ocupada pelos Medos até 553 a. C. Contudo, há fontes que nos permitem duvidar disso, assim como de que o império neobabilónico controlava a Síria e o norte da Mesopotâmia. Ver Curtis 2003, 157-67.

${ }^{6}$ Seria morto em Opis depois de ter ajudado Nabónido contra Ciro. Os acontecimentos são descritos na «Crónica de Nabónido». Ver Glassner 2004, 201-5 e Roux 1985, 327. 
Bel-sharra-usur. As suas convicções devem tê-lo levado a confrontos com segmentos da oligarquia e da população, particularmente, com o clero de Marduk.

A estada em Teima pode ser explicada como o resultado das divergências políticas entre Nabónido e o seu filho, enquanto a conquista do norte arábico foi motivado objetivos puramente imperialistas como a vasta riqueza da região. Tiveram lugar, por seu turno, deserções importantes como a de Góbrias, o governador do Gutium, que se uniu a Ciro'.

Não se sabe a razão do abandono de Teima por Nabónido, se uma ofensiva de Ciro preparadora do assalto a Babilónia ou outra qualquer ${ }^{8}$. O certo é que depois de dez anos este saiu de Teima em 542. O Ehulhul foi então solenemente inaugurado em Harran o regresso do rei a Babilónia permitiu o recomeço das cerimónias religiosas. Ignoram-se os detalhes das medidas tomadas para prevenir os perigos de um ataque que os últimos acontecimentos tornavam fáceis de prever. Assim, no Outono de 539 tudo se desenvolveu muito depressa, tendo Bel-sharra-usur sido morto no seu palácio, Nabónido sido feito prisioneiro e Ciro entrado como triunfador na capital.

A tradição lança dúvidas acerca da sorte do último rei. Segundo Xenofonte, o monarca foi morto, mas Josefo disse que foi exilado, o que estaria mais de acordo com a clemência e política tolerante de Ciro".

\section{A DIVISÃO DO PODER}

Nabónido confiou formalmente a «realeza» ao filho aquando a sua partida para o oeste e a Arábia. Ao fazê-lo, o rei não desejava abdicar, mas apenas institucionalizar a divisão das prerrogativas reais entre os dois. Algumas prerrogativas reais não foram legadas a Bel-sharra-usur, a saber: o título de rei, os anos de reinado que continuaram datados de acordo com os anos de Nabónido no trono, o não ter lugar o festival do Ano Novo durante a permanência em Teima, reassumido logo que este voltou, a construção de inscrições que sempre referiam

${ }^{7}$ Nada nos permite dizer que Gutium era uma província babilónica e que Ugbaru/Gobrias era um babilónico. A única referência é de Xenofonte (Cyr. 4.6.1-11), e deve-se ter cuidado quando tratamos essa obra como uma fonte. A julgar pelas fontes babilónicas, Gutium, é um termo geográfico bastante vago nesse período, e foi conquistado, por essa época, como Média. Segundo o Cilindro de Ciro, o rei Persa alcançou as suas primeiras vitórias no país de Gutium e as tropas dos Medos. Ugbaru podia ser governador de uma província persa que compreendia, pelo menos, partes do ocidente da Média e nordeste da Assíria e que delimitava com o território babilónico. É notável que tendo conquistado Babilónia, Ciro devolvesse os deuses e cidadãos deportados para Babilónia por Nabónido. De acordo com o texto do Cilindro de Ciro, essas cidades estendiam-se ao "território de Gutium», o que parece uma clara indicação de que a região não era parte do império neobabilónico.

${ }^{8}$ Acerca do destino de Nabónido, existe o testemunho de Beroso ( $F G r H 680$, frag. 10a) e a Profecia Dinástica. Veja-se Kuhrt 2013, 80-81 e Liverani 2003, 1-12.

${ }^{9}$ Veja-se Beaulieu 1989, 219-32. 
o rei como o dirigente ativo.

Outras prerrogativas foram partilhadas, como é o caso de refeições sacrificiais, as oferendas reais e os juramentos que prometiam o desempenho de vários tipos de serviços, e a divisão das forças armadas, marchando o rei para a Arábia com as «forças de Akkad».

Todavia, Bel-sharra-usur desempenhava alguns deveres, aparecendo em alguns documentos com a expressão «filho do rei» durante a sua regência. Nabónido não interferiu directamente nos assuntos de Babilónia durante o período de estada em Teima, mas manteve seguramente a correspondência com o filho.

Bel-sharra-usur rapidamente tomou uma posição proeminente no reino após a ascensão do seu pai. Manteve, para além das atividades oficiais, um lado privado explicitado em vários documentos. Como membro da família Nur-Sin e com a família Egibi, a que pertencem os documentos, o regente aparece como um proeminente homem de negócios e o chefe de uma Casa rica.

Aparentemente, a usurpação de 556 não envolveu apenas uma mudança de dirigente, mas também a confiscação das propriedades da família de Neriglissar em proveito de Bel-sharra-usur. Muitas ligações existiam, como a de Nabû-ahhê-iddina, chefe da Casa de Egibi. Este aparece em transações privadas do regente e dos seus servidores. Mesmo em reinados anteriores como o de Nabucodonosor ou do próprio Neriglissar. Nabû-ahhê-iddina foi um agente por mais de quarenta anos de Neriglissar, desempenhando a função com Bel-sharra-usur, tendo sido uma fonte de capital para os vários créditos.

\section{CONSIDERAÇõES FINAIS}

O final do império caldaico e a anexação persa são duas faces de uma mesma moeda. A tentativa de secularização por parte de Nabónido, modificando a estrutura dos templos dominados até então pelo clero do deus, diminuindo rendimentos a esses cleros, particularmente ao do deus Marduk, e as reformas fundiárias, foram agravadas, ao que tudo leva a crer, pelas questões religiosas propriamente ditas. O monarca babilónico foi visto como um desafio ao poder dos sacerdotes e o rei dos Persas como aquele que iria repor uma ordem violada anteriormente pelo soberano caldaico. Os Persas foram, para o clero de Marduk, libertadores. Eles assumiram as crenças e tradições babilónicas e assimilaram Babilónia ao Império que se dilatava e se dirigia para as costas do Mediterrâneo. O legado de sedentarização, urbanização e burocratização babilónicas foram recebidos como parte do Império Aqueménida num longo caminho de cosmopolitismo e universalidade. Como uma continuidade da tradição imperial no Próximo Oriente antigo. 


\section{Documentos}

\section{DOCUMENTO N ${ }^{\circ} 1$}

DIVISÃO DE CAMPOS POR ORDEM REAL

YOS VI,103 - «A terra arável de Bêl que, no mês Nisanu, o sétimo de Nabónido, rei de Babilónia, Belshazzar, o filho do rei, por ordem do rei, dividiu entre os oficiais râb sûtu.

$$
[\ldots] » "
$$

\section{DOCUMENTO $\mathrm{N}^{\circ} 2$ \\ EMPRÉSTIMO DE DINHEIRO}

Nbn 184 - «A respeito da Casa de Nabû-ahê-iddin, o filho de Shulâ, filho de Egibi, que é contígua à Casa de Bêl-iddin, filho de Rîmût, filho do oficial dikû, por três anos a Nabû-mukîn-ahi, o escriba de Belshazzar, o filho do rei, por uma mina e meia de prata ele deu com a provisão da qual não deve existir renda para a casa nem juro sobre o dinheiro. O madeiramento da casa ele renovará e qualquer abertura da parede e tapará. Após três anos o dinheiro, acrescido a uma e meia minas, Nabû-ahê-iddin a Nabû-mukîn-ahi dará e Nabû-mukîn-ahi deixará a casa à disposição de Nabû-ahê-iddin.»

\section{DoCUMENTO $\mathbf{N}^{\circ} 3$}

\section{TransaCÇão MONETÁria do AdMINISTRAdOR DE BEL-SARRA-USUR}

Nbn. 688 - «Relativo a uma mina e quinze siclos de prata, dívida e juro, a reivindicação de Nabu-sabit-qati, o mordomo de Bel-sarra-usur, o filho do rei, pela quantia devida por Bel-iddina, o filho de Bel-sum-iskun, filho de Sin-tabni, e pela qual o campo de sementeira que está entre as portas da cidade foi tomado como caução, pela dívida, na quantia de uma mina e quinze siclos, Nabu-sabit-qati recebeu de Itti-Marduk-balatu, o filho de Nabu-ahhe-iddin, filho de Egibi como for a debitado a Bel-iddina.

Testemunhas. Babilónia. $27^{\circ}$ dia do mês de Adaru, $12^{\circ}$ do reinado de Nabónido.»

\section{DOCUMENTO No 4 \\ ÉDITO DE BÊL-SHARRA-USUR}

YBT VI 103 - «(Édito repeitante) à terra arável de Bêl que Bêl-sharra-usur, o filho do rei, no mês de Nisannu do $7^{\circ}$ ano do reinado de Nabónido, rei de Babilónia, por ordem do rei, repartiu entre os grandes arrendatários.

Por um kurru de terra arável plantada (de palmeiras, a renda será) de 40 kurru (de tâmaras). 
Aí dentro estarão (contidos) 5 kurru (de tâmaras) para o salário dos arboricultores que escavarão canais e solo, farão o muro do pomar e suportarão os encargos que o filho do rei lhes confiara.

(Quanto às) obrigações e às rações de manutenção do chefe do distrito, dos encaregados de contas, dos encarregados de tirar as medidas e dos guardas-portão, as suas obrigações (serão) de $1 / 30$ kurru 5 qû $1 / 2$ por kurru (de rendas); dar-se-à ao chefe do distrito, aos contabilistas, aos medidores e aos porteiros reções de manutenção de 3 qû $1 / 2$ (de tâmaras) por kurru (de rendas); Estes poderão beneficiar disso (imediatamente).

Se o filho do rei dá 125 kurru de terra «de cultura»(o tomador) dará 1200 kurru de cevada por toda a (renda); por lote de 125 kurru (de terra), 5 kurru de terra arável lhe serão entregues para todas as rações de manutenção do chefe do distrito, dos contabilistas, dos medidores e dos porteiros.

Por cada arado dar-se-lhe-á 4 bois, 2 animais de cornos jovens, 4 agricultores. Os bois não deverão enfraquecer. Os instrumentos de ferro são levados em conta.

Por kurru (as rendas dos tomadores) acrescentarão à renda fundiária 1/30 de kurru 5 qû $1 / 2$ de cevada e de tâmaras como rações de manutenção (de Bêl) e as darão ao Esagil.

Eles entregarão a cevada e as tâmaras na totalidade no Esagil.

Por kurru (rendas) eles darão a mais da sua renda fundiária 3 qû $1 / 2$ de rações de manutenção ao chefe do distrito, aos contabilistas, aos medidores e aos porteiros.

No primeiro ano [o Esagil] dará 125 kurru de cevada para as sementeiras assim como 145 kurru de cevada para as rações de manutenção dos agricultores (à razão de) 4 kurru cada uma [e]para os animais do gado cornígero.» 


\section{Bibliografia}

Beaulieu, Paul-Alain. 1989. The Reign of Nabonidus King of Babylon 556-539 B.C. Michigan: Yale University.

Chavalas, Mark W. 2006. The Ancient Near East. Oxford: Blackwell Publishing. Curtis, J. 2003. "The Assyrian heartland in the period 612-539 BC." In Continuity of Empire (?): Assyria, Media, Persia, Padova, eds. Giovanni B. Lanfranchi, Michael Roaf et Robert Rollinger, 157-68. Padova: Sargon Editrice e Libreria.

Glasser, Jean-Jacques, dir. 2004. Chroniques Mésopotamiennes. Paris: Les Belles Lettres.

Grayson, A. Kirk. 2000. Assyrian and Babylonian Chronicles. Winona Lake: Eisenbrauns.

Joannès, Francis, dir. 2001. Dictionnaire de la Civilisation Mésopotamienne. Paris: Robert Laffont.

—2000. La Mésopotamie au 1er millénaire avant J.-C. Paris: Armand Colin.

Kuhrt, Amélie. 2010. The Persian Empire. A Corpus of Sources from the Achaemenid Period. London: Routledge.

Lecoq, Pierre. 1977. Les inscriptions de la Perse achéménique. Paris: Gallimard.

Liverani, M. 2003. “The Rise and Fall of Media." In Continuity of Empire (?): Assyria, Media, Persia, Padova, eds. Giovanni B. Lanfranchi, Michael Roaf et Robert Rollinger, 1-12. Padova: Sargon Editrice e Libreria.

Pritchard, James B., ed. (1950) 1992. Ancient New Eastern Texts. Relating to the Old Testament. Princeton: Princeton University Press.

Roux, George. 1985. La Mésopotamie. Essai d'histoire politique, économique et culturelle. Paris: Seuil.

Saggs, H. W. F. 1996. Babylonians. London: British Museum Press.

Wiseman, D. J. 1956. Chronicles of Chaldean Kings (626-556 B.C.) in the British Museum. London: The Trustees of the British Museum. 